\section{Microplastics in the gastrointestinal tracts of fish and the water from an urban prairie creek}

\author{
Samantha H. Campbell ${ }^{\mathrm{a}}$, Patrick R. Williamson ${ }^{\mathrm{a}}$, and Britt D. Hall ${ }^{\text {^ }}$ \\ ${ }^{a}$ Department of Biology, University of Regina, 3737 Wascana Parkway, Regina, SK S4S 0A2, Canada \\ *britt.hall@uregina.ca
}

\begin{abstract}
Microplastics are defined as any plastic with a diameter $\leq 5 \mathrm{~mm}$. Problems associated with these plastics such as contamination of both marine and freshwater environments and ingestion by aquatic organisms are of increasing concern. Our study quantifies the number of microplastics in a prairie creek immediately downstream of Regina, Saskatchewan, Canada. Water samples and five species of fish were collected from sample sites upstream and downstream of a wastewater treatment plant (WWTP) in the summers of 2015 and 2016. Samples were digested in either a $\mathrm{Fe}(\mathrm{II}) / \mathrm{H}_{2} \mathrm{O}_{2}$ or $\mathrm{NaClO}$ solution and observed under a microscope where plastics present were enumerated by colour and type. At least one microplastic was detected in $73.5 \%$ of fish and $95.6 \%$ of water samples, showing that the creek does, in fact, contain microplastics. Concentrations were higher in water from upstream sites, likely due to dilution of creek water by the release of treated effluent. The results of this study provide baseline conditions for the presence of plastics in the creek prior to a major upgrade of the WWTP scheduled for completion in 2016.
\end{abstract}

Key words: microplastics, microbeads, fish, Wascana Creek, water quality, contamination, North American Great Plains, Saskatchewan, wastewater

\section{Introduction}

The contamination of both marine and freshwater environments with microplastics, as well as their ingestion by freshwater organisms, is of increasing concern (Wagner et al. 2014; Eerkes-Medrano et al. 2015). Although no ubiquitous definition of microplastics exists, microplastics are largely considered to be plastic polymer debris with a diameter of $\leq 5 \mathrm{~mm}$ (Betts 2008; Barnes et al. 2009). This plastic debris can be ranked as primary, in which the particle was manufactured as a microplastic, or secondary, in which the particle was manufactured as a macroplastic ( $>5 \mathrm{~mm})$ and degraded to its present size (Cole et al. 2011; Rummel 2014). Primary microplastics largely consist of microbeads (tiny round plastics mainly used as abrasive scrubs) and are commonly found in hygiene, sandblasting, and medical products (Zitko and Hanlon 1991; Patel et al. 2009; Browne et al. 2011; Rochman et al. 2015). Secondary microplastics vary in form and origin, and often result from the breakdown of macroplastics through ultraviolet, microbial, and physical degradation (Browne et al. 2007; Rios et al. 2007; Moore 2008; Shah et al. 2008; Barnes et al. 2009; Ryan et al. 2009; Andrady 2011). Further categorization includes grouping based on shape as beads, fibers, and fragments. Microplastic fibers can be primary or secondary in nature and mainly originate from items such as clothing, fishing nets, and plastic bags (Browne et al. 2011; Claessens et al. 2013; 
Hartline et al. 2016). Fragmented microplastics are secondary plastics often originating from plastic objects that do not fray into fibers (Browne et al. 2011; Cole et al. 2011; Claessens et al. 2013; Mathalon and Hill 2014).

Microplastics can easily disperse in aquatic ecosystems due to their ubiquitous nature and buoyant properties (Cole et al. 2011; Wright et al. 2013). Many polymers that formulate microplastics have slightly lower densities than water, and this combined with their small size and relatively large surface area to volume ratio engenders microplastics' neutral buoyancies (Cole et al. 2011). This allows them to drift over great distances within aquatic currents or over vast expanses of land by wind (Cole et al. 2011; Mathalon and Hill 2014). Neutral buoyancy also contributes to their similar appearance to small aquatic organisms such as plankton. Plastic formulations that are denser than water tend to sink into the sediments (Ryan 2015). In addition, aggregates of microplastics and organic material such as biofilms may sink and contribute to the sequestration of microplastics in sediments (Teuten et al. 2009; Cole et al. 2011; Long et al. 2015; Fazey and Ryan 2016). In turn, microplastics may be ingested, either actively (e.g., by pelagic fish consuming them as they would plankton) or passively (e.g., benthic fish consuming them inadvertently when feeding in sediments). Once consumed, problems such as pseudo-satiation, blockage of the intestine, endocrine disruption through leached plasticizers, and contamination by adhered persistent organic pollutants can arise (Barnes et al. 2009; Talsness et al. 2009; Teuten et al. 2009; Lithner et al. 2011; Wright et al. 2013). Microplastics can end up being re-suspended due to bioturbation in the sediments, which facilitates cycles of ingestion, excretion, and settlement (Wright et al. 2013).

Although the majority of work to date has examined plastics in marine systems, studies showing prevalence in freshwaters have been increasing in numbers. Plastics in freshwaters were originally observed in the Laurentian Great Lakes (Eriksen et al. 2013); numerous studies since have detected microplastics in other freshwater systems. For example, the Global Water Research Coalition 2015 (GWRC 2016) summarized the extent of microplastic freshwater pollution and showed that European and North American rivers contain as many as 387 particles $\mathrm{m}^{-3}$ (McCormick et al. 2014; Lechner and Ramler 2015).

Earlier studies found microplastics in the influent of wastewater treatment plants (WWTPs) from both household and industrial operations. These plastics may be removed during primary phase separation treatment as well as lost to settling in aeration pond sediments during secondary treatment (Carr et al. 2016; Murphy et al. 2016); however, microplastics may pass through the treatment system and be released in treated effluent (Gregory 1996; Browne et al. 2007; Fendall and Sewell 2009). Small numbers per litre released in effluent can translate to large numbers of plastics in aquatic systems, considering the large volumes of treated effluent released from WWTPs worldwide. As a result, studies have shown that wastewater effluent is a source of microplastics to aquatic systems (see reviews in Estahbanati and Fahrenfeld 2016; Ziajahromi et al. 2016).

Our objective to determine if microplastics were present in the water and fish in Wascana Creek was supplemented by the examination of microplastics upstream and downstream of the City of Regina WWTP. The city of Regina WWTP services $\sim 200000$ people resulting in the release of between 73 and 81 million L.day ${ }^{-1}$ during the months we sampled. Until fall 2016, wastewater was treated at the Regina plant by phase separation in primary sedimentation vessels, followed by secondary treatment in aerated settling lagoons, phosphorous removal by the addition of aluminum salts, and UV disinfection prior to release into Wascana Creek (Razban 2010). We hypothesized that because phase separation likely allowed for the removal of microplastics and microplastics were likely sequestered in settling ponds due to the production of phytoplankton and biofilm-microplastic aggregates heavy enough to sink to lagoon sediments (Long et al. 2015; Carr et al. 2016; Fazey and Ryan 2016; Murphy et al. 2016), concentrations of microplastics would not differ upstream and downstream of 
the WWTP. To our knowledge, no one has examined the prevalence of microplastics in the water and fish in a northern prairie system (Anderson et al. 2016), thus our examination of microplastics in an urban creek downstream of Regina, Saskatchewan, Canada adds to a growing body of evidence that supports the ubiquitous nature of microplastics in freshwater systems.

\section{Methods}

\section{Site selection}

Three sampling sites were selected along Wascana Creek located on the northern outskirts of Regina in south-central Saskatchewan and sampled in July 2015 and July and August 2016 (Fig. 1). Wascana Creek is fed by Wascana Lake, a water storage system in the center of the city of Regina constructed in the late 1880s. There are no major population centers upstream of Regina. This area has a warm summer continental climate with strong seasonality and severe winters (Köppen-Geiger classification: Dfb). From 1991 to 2010, daily mean temperatures ranged from a mean winter temperature of $-14.7^{\circ} \mathrm{C}$ in January to a mean summer temperature of $18.9{ }^{\circ} \mathrm{C}$ in July (Environment Canada 2016). Mean precipitation ranged from $0.5 \mathrm{~mm}$ in December to $70.9 \mathrm{~mm}$ in June (Environment Canada 2016). Three sites were chosen in relation to Regina's WWTP

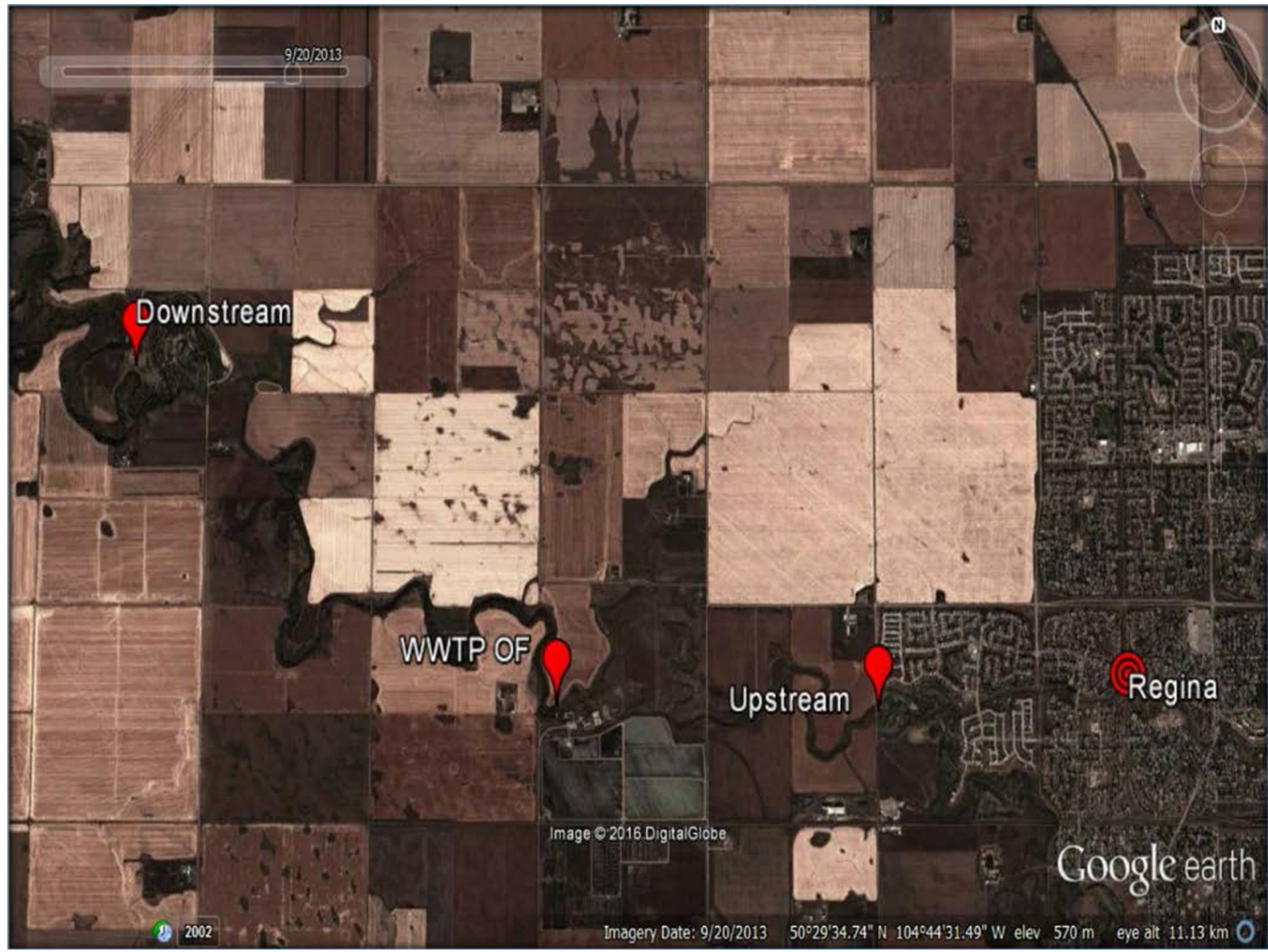

Fig. 1. Location of the three sampling sites northwest of the city of Regina, Saskatchewan, Canada. WWTP OF, wastewater treatment plant outflow. Map data attributable to Google Earth, Digital Globe 2016. 
Outflow (OF): $\sim 3 \mathrm{~km}$ upstream, at the OF, and $\sim 10 \mathrm{~km}$ downstream. Differences in weather at different sites were negligible. At the OF site, water was a mix of treated sewage and upstream water. There was no measurement to determine the proportion of each. The process in Regina's WWTP during the study period consisted of primary sedimentation, secondary treatment via aerated lagoons, chemical flocculation in tertiary clarifiers, and UV disinfection prior to discharge (Razban 2010). In fall 2016, an upgraded WWTP went online, which uses bioreactors to treat wastewater.

\section{Sample collection}

\section{Water}

Five individual water samples were collected at each site using an $80 \mu \mathrm{m}$ mesh conical net held in the center of the stream over a 5 min period in July 2015 and July and August 2016. In 2016, three were collected from each site in July, and due to weather concerns, two additional samples were collected in August. As there was no statistically significant difference in concentrations in July compared with August, we combined the data from those two dates. Flow was measured concurrently using a Swaffer ${ }^{\circ}$ Flow Meter. The particulates accumulated on the net were rinsed off with creek water into a glass jar and stored at $4{ }^{\circ} \mathrm{C}$ until analysis. Water conductivity $\left(\mu \mathrm{S} \cdot \mathrm{cm}^{-1}\right), \mathrm{pH}$, temperature $\left({ }^{\circ} \mathrm{C}\right)$, and dissolved oxygen (\%) were measured using a YSI 556 multiprobe sonde. Discharge of effluent records was obtained from the WWTP operators, EPCOR Prairie Water.

\section{Fish}

Target fish species were collected using seine nets, gill nets, conventional tackle, and minnow traps in June 2015. Five species of fish were collected: northern pike (Esox lucius), white sucker (Catostomus commersoni), emerald shiner (Notropis atherinoides), fathead minnow (Pimephales promelas), and five-spine stickleback (Eucalia inconstans). The majority of the samples were caught with seine net tows performed between two opposing gill nets to ensure any fish in that area would be caught using one of the two methods. Gill nets were set along the creek at intervals of approximately $10 \mathrm{~m}$ and were checked and reset every $30 \mathrm{~min}$. Minnow traps and conventional tackle were baited with dog food and leeches, respectively. Euthanization of fish was done using buffered tricaine methane/sulfonate (MS-222) as outlined by procedures approved by the Canadian Council on Animal Care (2010). Appropriate permits and protocols for animal care were obtained from the University of Regina Animal Utilization Protocol 15-08. Fish were euthanized, sorted into Ziploc ${ }^{\circledR}$ bags based on species, and put on ice for transport. In total 75 emerald shiners, 30 northern pike, 32 white suckers, 34 fathead minnows, and 10 five-spine stickelbacks were collected. The population of fish within the creek system was not measured. Fish in this system swim throughout the entirety of the creek over the course of the open water season, dispersing downstream depending on water depth and temperature as the season progresses (A. McCutcheon and B. Skatfeld, personal communication, 2016).

\section{Analysis}

\section{Water}

For all preparation and digestion of samples, metal or glass vessels were used, and lab coats were worn to prevent contamination from clothing. Water samples were sieved using a stacked series $(4750,500$, and $75 \mu \mathrm{m}$ mesh size), and material from each sieve was rinsed into beakers with deionized water. Wet peroxide oxidation was used to dissolve all organic material present in the sample (Masura et al. 2015). Approximately $20 \mathrm{~mL} 0.05 \mathrm{M} \mathrm{Fe}(\mathrm{II}) \mathrm{SO}_{4} \cdot 7 \mathrm{H}_{2} \mathrm{O}$ solution and $\sim 20 \mathrm{~mL} 30 \%$ hydrogen peroxide $\left(\mathrm{H}_{2} \mathrm{O}_{2}\right)$ were added slowly and left to react for $5 \mathrm{~min}$ (Masura et al. 2015). This mixture was heated to $75^{\circ} \mathrm{C}$ on a hot plate until bubbling, removed to cool, and then returned to the hot plate to further digest for $30 \mathrm{~min}$. Additional $\mathrm{H}_{2} \mathrm{O}_{2}$ was added as needed in $20 \mathrm{~mL}$ increments to dissolve all 
organic material (Masura et al. 2015). After the digestion, samples were sieved, rinsed into glass Petri dishes, and left to dry overnight in an oven at $100{ }^{\circ} \mathrm{C}$. Samples were covered with glass watch glasses and glass Petri dish tops during digestion and drying, respectively. Once dry, the samples were examined under a dissection microscope, and microplastics were visually enumerated and characterized by their size, shape, and colour. Suspected plastics were then confirmed to be plastic using hot needle testing, which involved the application of a heated needle tip to each plastic to confirm that it would melt. Although characterization using Raman spectroscopy would have been helpful in identifying the nature of the plastics, budgets did not allow this. In 2016, samples were treated with added conditions that included filtering all reagents and rinse water before use and completing all tasks inside a positive pressure laminar hood. The purpose of these added conditions was to reduce contamination by transparent, colourless (hereafter referred to as clear) fibers that occurred in the laboratory (see below); similar methods were used by Luscher et al. (2013).

Fish

Entire gastrointestinal (GI) tracts were removed from each fish by creating an incision just below the throat and carefully cutting down the ventral side of the fish to the anal opening. Samples were stored in ethanol until digestion using 10\% $\mathrm{NaClO}$ solution (diluted with deionized water in a 1:3 $v / v$ ratio) (Collard et al. 2015). Intact GI tracts from specimens smaller than $5.0 \mathrm{~g}$ were digested completely after being cut into small pieces with dissection scissors. In specimens larger than $5.0 \mathrm{~g}$, GI tracts were cut open and rinsed with ethanol prior to the filtration process due to the thicker digestive epithelium. The rinsate along with the storage ethanol was filtered using a 5.0 micron polycarbonate membrane filter and glass filter train into a Teflon bomb to digest overnight allowing digestion of organic material. A subsequent 5 min digestion in $\sim 30 \mathrm{~mL} \mathrm{HNO}_{3}: \mathrm{NaClO}(1: 10 v / v)$ solution was performed if organic material was still evident after initial digestion, as it often was with the larger GI tracts (Collard et al. 2015).

After digestion, samples were filtered on 5.0 micron polycarbonate membrane filters, and particulates were rinsed onto glass Petri dishes with $95 \%$ methanol. Samples were dried in an oven at $100{ }^{\circ} \mathrm{C}$ overnight to allow the methanol to evaporate. It is important to note that methanol is extremely flammable and alternative methods of drying are encouraged. Once the samples were dry, enumeration of microplastics was performed under a dissection microscope as described above.

\section{Statistical analysis}

Shapiro-Wilk's tests were used to confirm that both fish and water data were normally distributed. Two-factor analysis of variances (ANOVAs) (without replication) were completed to compare the mean numbers and concentrations of microplastics in water collected at three sites in 2015 and 2016. Because fish move among sites, we did not test site-to-site differences in fish. However, we did test species differences using Kruskal-Wallis' one-way ANOVA on ranks and subsequent Tukey's pairwise multiple comparison.

\section{Issues of contamination}

Microplastics are very lightweight and mobile, and therefore, caution must be used while analyzing samples to guarantee that no particles from the air or water in the laboratory contaminate the samples (Mathalon and Hill 2014; Masura et al. 2015). We noticed in initial samples that there were a large number of clear plastic fibers inside and outside of the glass Petri plates. We measured microplastics in a series of blanks and found that limiting access to unfiltered air (by working in a positive pressure hood) and plastic (by the use of glass and metal equipment) and using filtered reagents reduced the contaminant microplastics (Tables S1 and S2). It should be noted that the clear fibers that were contaminants in the actual samples were impossible to distinguish from the 
clear fibers that were non-contaminants from the creek itself, and as such we removed all clear fibers from the results of the study.

\section{Results and discussion}

\section{Microplastics in water}

Microplastics of varying shapes and colours were found in water at all sites in both 2015 and 2016 (Tables S3 and S4). Concentrations of microplastics were significantly higher at upstream sites $\left(3.8 \pm 1.2\right.$ and $7.7 \pm 2.0$ microplastics $\cdot \mathrm{m}^{-3}$ in 2015 and 2016 , respectively) compared with those at the WWTP OF $\left(1.0 \pm 0.2\right.$ and $1.0 \pm 0.4$ microplastics $\cdot \mathrm{m}^{-3}$ in 2015 and 2016 , respectively $)$ and farther downstream $\left(3.7 \pm 0.3\right.$ and $0.9 \pm 0.3$ microplastics $\cdot \mathrm{m}^{-3}$ in 2015 and 2016 , respectively; $\left.F_{1,2}=8.45, p=0.002\right)$ and in 2016 compared with $2015\left(F_{1,1}=14.65, p<0.001\right.$; Fig. 2$)$. The concentrations of microplastics in water were confounded by a statistical interaction between year sampled and site collected $\left(F_{1,2}=6.61, p=0.005\right)$, and while we are cautious in interpreting the main effects due to the interaction effect, it is likely that the interaction effect is due to the fact that the concentrations were greater upstream in both years and flow rates differed between years (Table 1).

The reduction of concentrations from the upstream site suggests possible sequestration within, or loss from, the creek. Sequestration and loss could have occurred via wind removal, burial in sediments and near shore vegetation, as well as via ingestion by organisms as they travelled downstream (Gregory 1996; Browne et al. 2007; Fendall and Sewell 2009; Cole et al. 2011; Mathalon and Hill 2014). However, if concentrations decreased as we moved downstream due to only loss, we would have expected to observe a further decrease in concentrations at the downstream site. This was not the case; concentrations were lowest at the WWTP, suggesting that the release of treated water from the WWTP could have potentially increased flow rates, thus increasing the dilution of microplastics

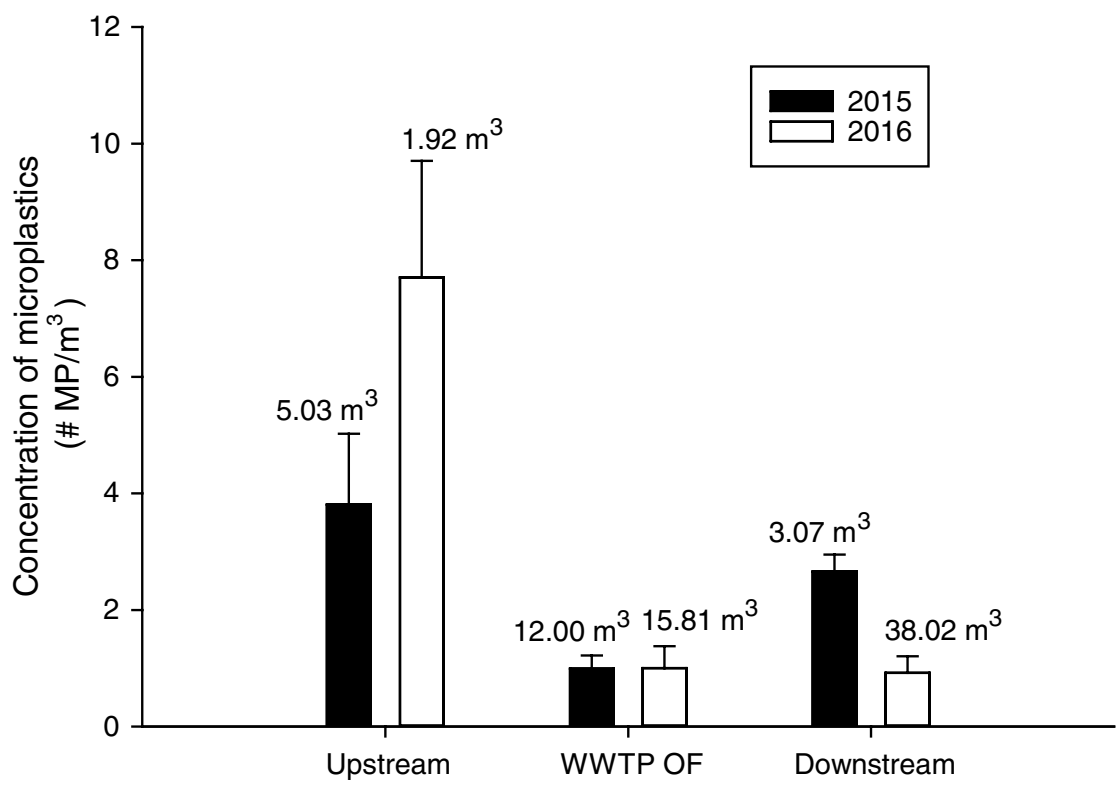

Fig. 2. The mean concentration in a cubic meter $\left(\mathrm{m}^{3}\right)$ of microplastics \pm standard error in water across sampling sites in 2015 and 2016. The mean volume of water sampled is presented above the bars; volume sampled in 2016 was the mean volume from two dates. Sample size $n=5$ for all. Error bars depict the standard errors of the means. MP, microplastics; WWTP OF, wastewater treatment plant outflow. 
Table 1. Sample information and data, and volume of water sampled calculated using the following equation: volume sampled $\left(\mathrm{m}^{3}\right)=$ flow rate $\left(\mathrm{m} \cdot \mathrm{s}^{-1}\right) \times$ time sampled $(\mathrm{s}) \times 0.062 \mathrm{~m}^{2} \times 0.75 \times 1000 \mathrm{~L} \cdot \mathrm{m}^{-3}$, where $0.062 \mathrm{~m}^{2}=$ mouth opening of the net, $0.75=$ net efficiency.

Sample site Sample number Year Flow rate $\left(\mathrm{m} \cdot \mathrm{s}^{-1}\right)$ Sample time (s) Volume of water sampled $\left(\mathrm{m}^{3}\right)$

\begin{tabular}{lccccc} 
Upstream & $1-5$ & 2015 & 0.36 & 300 & 5022.00 \\
\hline WWTP OF & $1-5$ & 2015 & 0.86 & 300 & 11997.00 \\
\hline Downstream & $1-5$ & 2015 & 0.22 & 300 & 3069.00 \\
\hline Upstream & $1-3$ & 2016 & 0.11 & 300 & 1559.05 \\
\hline WWTP OF & $1-3$ & 2016 & 0.44 & 300 & 6096.15 \\
\hline Downstream & $1-3$ & 2016 & 2.00 & 300 & 27927.90 \\
\hline Upstream & $4-5$ & 2016 & 0.16 & 300 & 2268.27 \\
\hline WWTP OF & $4-5$ & 2016 & 0.27 & 300 & 3826.49 \\
\hline Downstream & $4-5$ & 2016 & 5.04 & 300 & 70299.07 \\
\hline
\end{tabular}

Note: WWTP OF, wastewater treatment plant outflow.

in our samples. In addition, year-to-year differences in flow rates of the creek could have been due to differing precipitation rates. Discharge of effluent records for the dates of sampling showed that between 24.1 and 77.4 million $\mathrm{L}$ of effluent were released to the creek on our sampling days (77.4, 77.3, and 24.1 million L on 22 July 2015, 18 July 2016, and 17 August 2016, respectively); volumes high enough to have caused a dilution effect on concentrations. Therefore, differences in concentrations with sampling site are likely a combination of settling and dilution. There is also the possibility that the concentrations at the downstream site represented a contribution of microplastics from the WWTP combined with a decrease in concentrations due to settling. Our work provides no solid evidence to suggest that the WWTP aided in either eliminating or adding microplastics to Wascana Creek.

These results are similar to other studies of rivers, with a few key differences in the type and quantity of microplastics observed. Baldwin et al. (2016) sampled 29 tributaries to the Great Lakes and found between 0.5 and 32 microplastics $\cdot \mathrm{m}^{-3}$. Concentrations of most types of plastics were higher in areas with more urban runoff, although fiber concentrations did not change with this parameter (Baldwin et al. 2016). In California, Moore et al. (2005) found considerably higher concentrations (average $=30-109$ microplastics $\cdot \mathrm{m}^{-3}$ ) in water samples from the Los Angeles River than in our samples from Wascana Creek. This is likely due to a higher population in the Los Angeles River catchment area compared with that surrounding Wascana Creek, as well as the fact that Moore et al. (2005) examined concentrations in rivers after heavy precipitation and related runoff events. Studies have found that microplastic concentrations increased after storms, suggesting that rainwater may re-suspend plastics previously sequestered in the sediments as well as wash plastics present in riparian areas into the aquatic system (Lattin et al. 2004; Baldwin et al. 2016). In other sites in California (Coyote Creek and San Gabriel rivers (Moore et al. 2005), and Santa Monica Bay (Lattin et al. 2004)), concentrations were more similar to ours with average values ranging from $<1$ to 22 microplastics $\mathrm{m}^{-3}$ depending on the proximity to the shore line.

\section{Microplastics found in fish GI tracts}

Of 181 fish sampled, $73.5 \%$ had between 1 and 20 microplastics in their GI tracts, ranging from 50.0\% (fathead minnows) to $83.3 \%$ (northern pike; Fig. 3A). There was a significant difference in the number of microplastics found among species, with northern pike having significantly more compared 

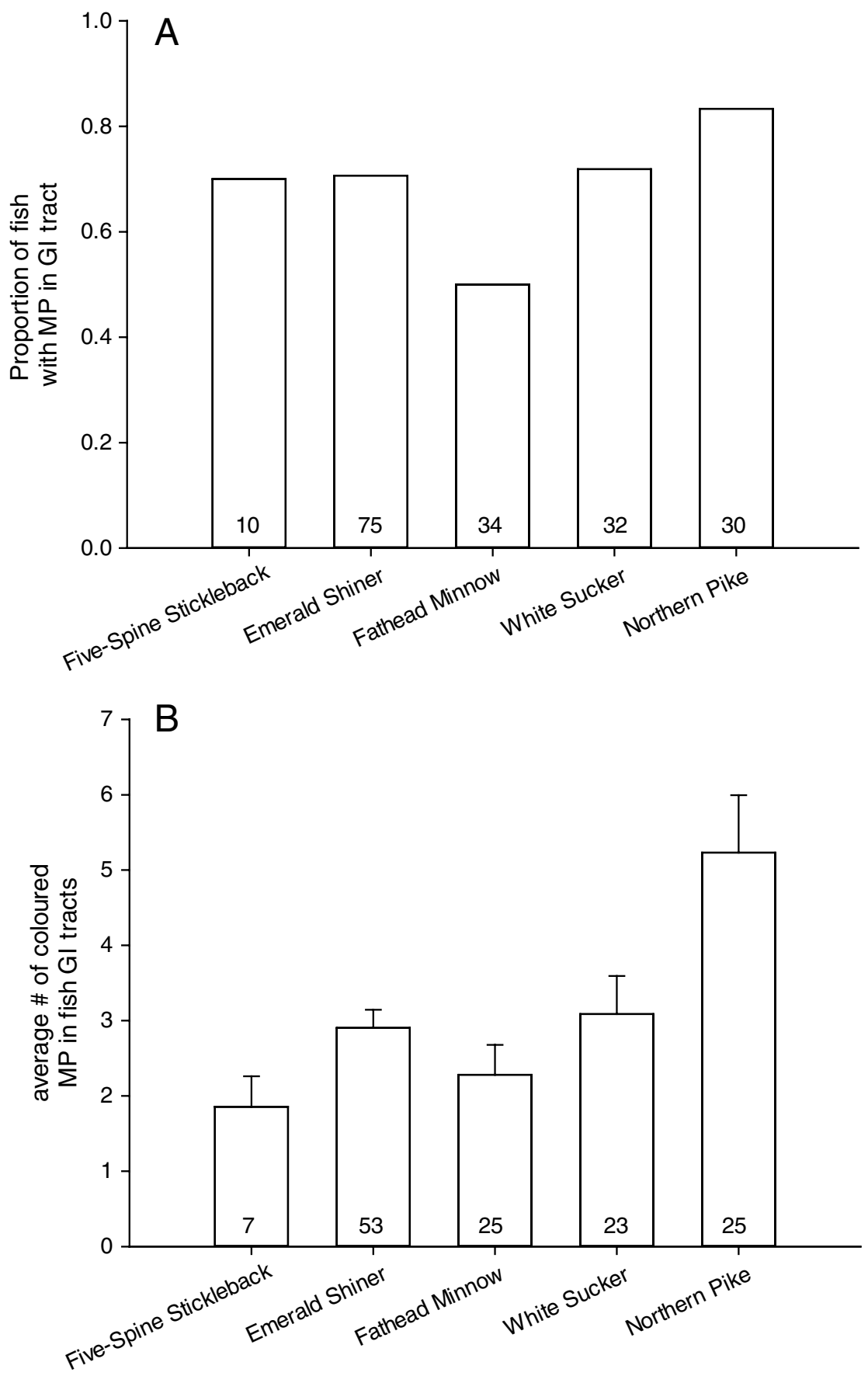

Fig. 3. (A) Proportion of fish caught with microplastics present in the gastrointestinal tract, and (B) mean number of MP ( \pm standard error) in GI tracts of five fish species. Numbers on bars represent the total number of fish caught for each species in (A) and the number of fish with one or more microplastics in (B). MP, microplastics; GI, gastrointestinal. 
with other species of fish $(H=16.487, p=0.002$; Fig. 3B). These percentages may be explained by differences in the feeding habits of the various species. For example, benthivores, such as white suckers, fathead minnows, and sticklebacks, are likely exposed to microplastics that have settled onto the sediments, whereas planktivores such as shiners would be more likely to consume microplastics suspended in the water column. We did not see a significant difference in the number of microplastics in benthivorous and planktivorous fish. We did observe significantly more plastics in northern pike, and because microplastics have been shown to accumulate in the GI tracts of many organisms, it is reasonable to hypothesize that, as apex predators, pike may have increased concentrations due to trophic transfer from the smaller species (Brillant and MacDonald 2000; Browne et al. 2008). In addition to the clear, loose fibers that we classified as contamination in both water and fish samples, we observed clear fibers bunched into balls in the fish GI tracts. Although due to the nature of consolidation of these fibers, we suspect that these were not contamination, we were conservative and removed these from our data set. The large balls of clear fibers were found in many of the northern pike stomachs. Although we cannot speculate if these were indeed consumed plastics, it is worth noting that $\sim 15.0 \%$ of northern pike contained these fibers.

The majority of the northern pike were caught at the upstream site, and the majority of emerald shiners were caught at the downstream site, with none at the upstream site. The majority of fish move upstream in the spring to spawn, dispursing once the water depths allow them to move back downstream (A. McCutcheon and B. Skatfeld, personal communication, 2016). Because the fish are moving throughout the system, we could not analyze site-to-site differences.

There have been very few reports of microplastics in freshwater fish. The prevalence of fish containing microplastics in our study was considerably higher than the earliest reports examining microplastics in wild freshwater fish. Sanchez et al. (2014) observed microplastics in GI tracts of $12 \%$ of wild gudgeons (Gobio gobio) from French rivers, slightly lower values compared with Biginagwaa et al. (2016) who observed plastics in $20 \%$ of both Nile perch (Lates niloticus) and Nile tilapia (Oreochromis niloticus) in Lake Victoria, Africa, whereas Fazey and Ryan (2016) observed microplastics in the guts of $45 \%$ of two species of freshwater sunfish in a Texan river. Our values were similar to those of Silva-Cavalcanti et al. (2017) who found microplastics in the GI tracts of $83 \%$ of the freshwater catfish species Hoplosternum littorale in South America. However, we caution the comparison with microplastics in fish in other studies due to the fact that feeding behaviours influence exposure to microplastics (Wright et al. 2013; Setälä et al. 2014). As the literature on microplastics in freshwater fish becomes more robust, comparison of microplastics in fish with similar feeding habits in different aquatic systems will become increasingly possible.

\section{Types of microplastics}

The majority of microplastics found in both the water and the fish GI tracts were fibers and fragments (Table 2), similar to other studies examining microplastics in mussels, water, sediments, and fish (Luscher et al. 2013; Free et al. 2014; Mathalon and Hill 2014; Baldwin et al. 2016). Water samples were dominated by fibers $(89.5 \%)$, with a lesser proportion of fragments $(10.2 \%)$ and less than $1 \%$ beads (Table 2). The low values of microbeads found in the water were surprising. We speculate that microbeads are proportionally more prevalent in wastewater influent due to household and industrial waste as the source of these plastics, and that due to extended water retention times in aerobic settling ponds the microbeads were sequestered in the WWTP works.

We observed similar proportions of fibers (47.7\%) and fragments (42.6\%) in fish GI tracts. The proportion of fragments in the fish GI tracts was four times higher than the proportion in water. We 
Table 2. Characterization of microplastic types found in water and fish gastrointestinal tracts.

\begin{tabular}{lccccc}
\cline { 3 - 5 } $\begin{array}{l}\text { Microplastic } \\
\text { type }\end{array}$ & $\begin{array}{c}\text { Total } \\
\text { number }\end{array}$ & $\begin{array}{c}\text { Mean number } \\
\text { per sample }\end{array}$ & & $\begin{array}{c}\text { Total } \\
\text { number }\end{array}$ & $\begin{array}{c}\text { Mean number } \\
\text { per sample }\end{array}$ \\
Fragments & 61 & $1.39 \pm 0.34$ & & 186 & $1.40 \pm 0.22$ \\
Fibers & 536 & $12.48 \pm 2.46$ & & 208 & $1.56 \pm 0.14$ \\
Beads & 2 & $0.05 \pm 0.03$ & & 42 & $0.32 \pm 0.06$ \\
\hline
\end{tabular}

Note: Data from water samples collected in 2015 and 2016 have been combined. GI, gastrointestinal.

speculate that this suggested selective uptake of fragments could be due to benthic feeding habits exposing fish to fragments sequestered in sediments. The proportion of fibers in fish GI tracts were similar to those reported by Silva-Cavalcanti et al. (2017), who observed 47\% fibers in South American catfish, and Jabeen et al. (2017), who found between $57 \%$ and $88 \%$ in six species of freshwater fish in China. The vast majority of microplastics in the guts of sunfish from a river in central Texas were threads (96\%) (Fazey and Ryan 2016). Again, we caution the comparison of results among fish with different feeding habits.

Earlier studies found plastic types termed "foams and films" (Luscher et al. 2013; Free et al. 2014); however, nothing of this class was found in our study. This may also explain variation in the proportion of fibers and fragments found in our study. Free et al. (2014) found mainly fragments in water samples; however, they were looking at a remote mountain lake, not a small creek receiving treated wastewater. This distinction is important because the location and source of microplastic pollution have a direct effect on the concentrations of microplastics in the water body (Browne et al. 2011; Cole et al. 2011; Free et al. 2014). Fibers tend to be lightweight and can stay suspended in the water column for longer periods of time than the denser fragments and beads. Different locations will contain different microplastic types depending on the original sources of plastics (Cole et al. 2011; Wright et al. 2013). Further research is needed to determine the origin of the microplastics in our system.

Our study used very conservative methods to deal with contamination by clear fibers. We ran statistical analysis on both the water and fish data including the clear fibers to determine if the exclusion of the clear fibers influenced our conclusions. With the water data, test results were consistent between the two data sets. For the fish data, significant differences among species were lost when the tests were run including the clear fibers.

\section{Conclusions}

Three types of microplastics were observed in both water and fish in Wascana Creek. Although all five species of fish were found to have microplastics in their GI tracts, northern pike had significantly higher values than emerald shiners and fathead minnows. On the whole, this study shows that microplastics are present in Wascana Creek, and that further studies will be required to determine the source of the microplastics, the habits of the organisms ingesting the microplastics, the toxicants absorbed and emitted by the microplastics, and methods for remediation that may help diminish microplastic numbers in the creek. Although jurisdictions that have instigated bans on microbeads in personal products are to be commended, our research suggests that plastic fibers may be more prevalent in freshwater systems, suggesting that a reduction of plastic use needs to be more comprehensive than banning microbeads in personal care products. 
Our hypothesis that concentrations of microplastics would be similar in downstream compared with upstream sites due to sequestration in the WWTP was not supported, in part because of the unexpected high concentrations found at the upstream site. Although we showed that concentrations downstream of the WWTP were not elevated, suggesting that the WWTP was not a large source of microplastics, our study design could not determine if site-to-site differences were due to losses in the creek or dilution of plastics due to WWTP effluent. Further studies should examine microplastics in treated effluent directly.

In late summer 2016, Regina's WWTP was upgraded to a modern system using bioreactive processes. As a result, settling ponds became obsolete and were taken offline. Using the previous system, wastewater was sequestered in settling ponds for weeks to months which may have allowed sufficient time for biofilms to form on plastics leading to the sequestration of plastics in lagoon sediments. In the new system, the residence time of wastewater in the treatment plant has been significantly reduced, thus creating the potential to reduce sequestration of plastics in sediment lagoons. Now that the upgraded WWTP is fully operational, we suggest that this study be repeated to determine if reduced processing time has resulted in increased concentrations of microplastics downstream of the WWTP.

\section{Acknowledgements}

This work was supported by the Saskatchewan Fish and Wildlife Development Fund. We thank Drs. R Manzon, P Leavitt, and K Finlay for providing laboratory and field equipment and J Dickenson, T Blampied, C McCowan, and L Whitehouse for their help in sample collection. K Gallant from EPCOR Water Prairies provided discharge records, and E Joyce provided netting material for blanks. A McCutcheon and B Skatfeld, Saskatchewan Ministry of Environment, provided information about the extent of fish swimming in the creek during open water season.

\section{Author contributions}

Conceived and designed the study: PRW, BDH. Performed the experiments/collected the data: SHC, PRW. Analyzed and interpreted the data: SHC, BDH. Contributed resources: BDH. Drafted or revised the manuscript: SHC, BDH.

\section{Competing interests}

The authors have declared that no competing interests exist.

\section{Data accessibility statement}

All relevant data are within the paper and in the Supplementary Material.

\section{Supplementary material}

The following Supplementary Material is available with the article through the journal website at doi:10.1139/facets-2017-0008

Supplementary Material 1

\section{References}

Anderson JC, Park BJ, and Palace VP. 2016. Microplastics in aquatic environments: Implications for Canadian ecosystems. Environmental Pollution, 218: 269-280. PMID:27431693. doi:10.1016/j. envpol.2016.06.074. 
Andrady AL. 2011. Microplastics in the marine environment. Marine Pollution Bulletin, 62: 15961605. PMID:21742351. doi:10.1016/j.marpolbul.2011.05.030.

Baldwin AK, Corsi SR, and Mason SA. 2016. Plastic debris in 29 Great Lakes tributaries: Relations to watershed attributes and hydrology. Environmental Science \& Technology, 50: 10377-10385. PMID:27627676. doi:10.1021/acs.est.6b02917.

Barnes DK, Galgani F, Thompson RC, and Barlaz M. 2009. Accumulation and fragmentation of plastic debris in global environments. Philosophical Transactions of the Royal Society B: Biological Sciences, 364: 1985-1998. PMID:19528051. doi:10.1098/rstb.2008.0205.

Betts K. 2008. Why small plastic particles may pose a big problem in the oceans. Environmental Science \& Technology, 42: 8995. PMID:19174862. doi:10.1021/es802970v.

Biginagwaa FJ, Mayomaa BS, Shashouad Y, Syberga K, and Khan FR. 2016. First evidence of microplastics in the African Great Lakes: recovery from Lake Victoria Nile perch and Nile tilapia. Journal of Great Lakes Research, 42: 146-149. doi:10.1016/j.jglr.2015.10.012.

Brillant M, and MacDonald B. 2000. Postingestive selection in the sea scallop, Placopecten magellanicus (Gmelin): the role of particle size and density. Journal of Experimental Marine Biology and Ecology, 253: 211-227. PMID:11033365. doi:10.1016/S0022-0981(00)00258-6.

Browne MA, Galloway T, and Thompson R. 2007. Microplastic-an emerging contaminant of potential concern? Integrated Environmental Assessment and Management, 3: 559-561. PMID:18046805. doi:10.1002/ieam.5630030412.

Browne MA, Dissanayake A, Galloway TS, Lowe DM, and Thompson RC. 2008. Ingested microscopic plastic translocates to the circulatory system of the mussel, Mytilus edulis (L.). Environmental Science \& Technology, 42: 5026-5031. PMID:18678044.

Browne MA, Crump P, Niven SJ, Teuten E, Tonkin A, Galloway T, et al. 2011. Accumulation of microplastic on shorelines worldwide: sources and sinks. Environmental Science \& Technology, 45: 9175-9179. PMID:21894925. doi:10.1021/es201811s.

Canadian Council on Animal Care. 2010. Guide to the care and use of experimental animals [online]: Available from ccac.ca/en_/standards/guidelines.

Carr SA, Liu J, and Tesoro AG. 2016. Transport and fate of microplastic particles in wastewater treatment plants. Water Research, 91: 174-182. PMID:26795302. doi:10.1016/j.watres.2016.01.002.

Claessens M, Van Cauwenberghe L, Vandegehuchte MB, and Janssen C. 2013. New techniques for the detection of microplastics in sediments and field collected organisms. Marine Pollution Bulletin, 70: 227-233. PMID:23601693. doi:10.1016/j.marpolbul.2013.03.009.

Cole M, Lindeque P, Halsband C, and Galloway TS. 2011. Microplastics as contaminants in the marine environment: a review. Marine Pollution Bulletin, 62: 2588-2597. PMID:22001295. doi:10.1016/j.marpolbul.2011.09.025.

Collard F, Gilbert B, Eppe G, Parmentier E, and Das K. 2015. Detection of anthropogenic particles in fish stomachs: an isolation method adapted to identification by Raman spectroscopy. Archives of Environmental Contamination and Toxicology, 69: 331-339. PMID:26289815. doi:10.1007/ s00244-015-0221-0. 
Eerkes-Medrano D, Thompson RC, and Aldridge DC. 2015. Microplastics in freshwater systems: a review of the emerging threats, identification of knowledge gaps and prioritisation of research needs. Water Research, 75: 63-82. PMID:25746963. doi:10.1016/j.watres.2015.02.012.

Environment Canada. 2016. Canadian Climate Normals 1981-2010 [online]: Available from climate.weather.gc.ca/climate_normals/results_1981_2010_e.html?searchType=stnProv\&lstProvince= SK\&txtCentralLatMin $=0 \& t x t C e n t r a l L a t S e c=0 \& t x t$ CentralLongMin $=0 \&$ txtCentralLongSec $=0 \& \operatorname{stnID}=$ 3002\&dispBack=0.

Eriksen M, Mason S, Wilson S, Box C, Zellers A, Edwards W, et al. 2013. Microplastic pollution in the surface waters of the Laurentian Great Lakes. Marine Pollution Bulletin, 77: 177-182. PMID:24449922.

Estahbanati S, and Fahrenfeld NL. 2016. Influence of wastewater treatment plant discharges on microplastic concentrations in surface water. Chemosphere, 162: 277-284. PMID:27508863. doi:10.1016/j.chemosphere.2016.07.083.

Fazey FMC, and Ryan PG. 2016. Biofouling on buoyant marine plastics: an experimental study into the effect of size on surface longevity. Environmental Pollution, 210: 354-360. PMID:26803792. doi:10.1016/j.envpol.2016.01.026.

Fendall LS, and Sewell MA. 2009. Contributing to marine pollution by washing your face: microplastics in facial cleansers. Marine Pollution Bulletin, 58: 1225-1228. PMID:19481226. doi:10.1016/j. marpolbul.2009.04.025.

Free C, Jensen O, Mason S, Eriksen M, Williamson N, and Boldgiv B. 2014. High-levels of microplastic pollution in a large, remote, mountain lake. Marine Pollution Bulletin, 85: 156-163. PMID:24973278. doi:10.1016/j.marpolbul.2014.06.001.

Gregory M. 1996. Plastic 'scrubbers' in hand cleansers: a further (and minor) source for marine pollution identified. Marine Pollution Bulletin, 32: 867-871. doi:10.1016/S0025-326X(96)00047-1.

GWRC. 2016. Global Water Research Coalition [online]: Available from globalwaterresearch coalition.net/.

Hartline NL, Bruce NJ, Karba SN, Ruff EO, Sonar SU, and Holden PA. 2016. Microfiber masses recovered from conventional machine washing of new or aged garments. Environmental Science \& Technology, 50: 11532-11538. PMID:27689236. doi:10.1021/acs.est.6b03045.

Jabeen K, Su L, Li J, Yang D, Tong C, Mu J, et al. 2017. Microplastics and mesoplastics in fish from coastal and fresh waters of China. Environmental Pollution, 221: 141-149. PMID:27939629. doi:10.1016/j.envpol.2016.11.055.

Lattin G, Moore C, Zellers A, Moore S, and Weisberg S. 2004. A comparison of neustonic plastic and zooplankton at different depths near the southern California shore. Marine Pollution Bulletin, 49: 291-294. PMID:15341821. doi:10.1016/j.marpolbul.2004.01.020.

Lechner A, and Ramler D. 2015. The discharge of certain amounts of industrial microplastic from a production plant into the River Danube is permitted by the Austrian legislation. Environmental Pollution, 200: 159-160. PMID:25734504. doi:10.1016/j.envpol.2015.02.019.

Lithner D, Larsson $\AA$, and Dave G. 2011. Environmental and health hazard ranking and assessment of plastic polymers based on chemical composition. Science of the Total Environment, 409: 3309-3324. PMID:21663944. doi:10.1016/j.scitotenv.2011.04.038. 
Long M, Moriceau B, Gallinari M, Lambert C, Huvet A, Raffray J, et al. 2015. Interactions between microplastics and phytoplankton aggregates: Impact on their respective fates. Marine Chemistry, 175: 39-46. doi:10.1016/j.marchem.2015.04.003.

Luscher A, McHugh M, and Thompson R. 2013. Occurrence of microplastics in the gastrointestinal tract of pelagic and demersal fish from the English Channel. Marine Pollution Bulletin, 67: 94-99. PMID:23273934. doi:10.1016/j.marpolbul.2012.11.028.

Masura J, Baker J, Foster G, Arthur C, and Herring C. 2015. Laboratory methods for the analysis of microplastics in the marine environment: recommendations for quantifying synthetic particles in waters and sediments NOAA Technical Memorandum, NOS-OR\&R-48.

Mathalon A, and Hill P. 2014. Microplastic fibers in the intertidal ecosystem surrounding Halifax Harbor, Nova Scotia. Marine Pollution Bulletin, 81: 69-79. PMID:24650540. doi:10.1016/j. marpolbul.2014.02.018.

McCormick A, Hoellein TJ, Mason SA, Schluep J, and Kelly JJ. 2014. Microplastic is an abundant and distinct microbial habitat in an urban river. Environmental Science \& Technology, 48: 11863-11871. PMID:25230146. doi:10.1021/es503610r.

Moore CJ. 2008. Synthetic polymers in the marine environment: a rapidly increasing, long-term threat. Environmental Research, 108: 131-139. PMID:18949831. doi:10.1016/j. envres.2008.07.025.

Moore CJ, Lattin GL, and Zellers AF. 2005. Working our way upstream: a snapshot of land-based contributions of plastic and other trash to Coastal Waters and Beaches of Southern California. Algalita Marine Research Foundation, Long Beach, California.

Murphy F, Ewins C, Carbonnier F, and Quinn B. 2016. Wastewater treatment works (WwTW) as a source of microplastics in the aquatic environment. Environmental Science \& Technology, 50: 5800-5808. PMID:27191224. doi:10.1021/acs.est.5b05416.

Patel M, Goyal B, Bhadada S, Bhatt J, and Amin A. 2009. Getting into the brain: approaches to enhance brain drug delivery. CNS Drugs, 23: 35-58. doi:10.2165/0023210-20092301000003.

Razban B. 2010. Novel protocols for the identification of significant bacterial consormial activities in the City of Regina aerobic wastewater treatment plant. MASc, University of Regina, Regina, Saskatchewan. 87 p.

Rios LM, Moore C, and Jones PR. 2007. Persistent organic pollutants carried by synthetic polymers in the ocean environment. Marine Pollution Bulletin, 54: 1230-1237. PMID:17532349. doi:10.1016/j. marpolbul.2007.03.022.

Rochman C, Kross S, Armstrong J, Bogan M, Darling E, Green S, et al. 2015. Scientific evidence supports a ban on microbeads. Environmental Science \& Technology, 49: 10759-10761. PMID:26334581. doi:10.1021/acs.est.5b03909.

Rummel C. 2014. Occurrence and potential effects of plastic ingestion by pelagic and demersal fish from the North Sea and Baltic Sea. Johannes Gutenberg-Universität Mainz, Mainz, Germany.

Ryan PG. 2015. Does size and buoyancy affect the long-distance transport of floating debris? Environmental Research Letters, 10: 084019. doi:10.1088/1748-9326/10/8/084019. 
Ryan P, Moore C, van Franeker J, and Moloney C. 2009. Monitoring the abundance of plastic debris in the marine environment. Philosophical Transactions of the Royal Society B: Biological Sciences, 364: 1999-2012. PMID:19528052. doi:10.1098/rstb.2008.0207.

Sanchez W, Bender C, and Porcher JM. 2014. Wild gudgeons (Gobio gobio) from French rivers are contaminated by microplastics: preliminary study and first evidence. Environmental Research, 128: 98-100. doi:10.1016/j.envres.2013.11.004.

Setälä O, Fleming-Lehtinen V, and Lehtiniemi M. 2014. Ingestion and transfer of microplastics in the planktonic food web. Environmental Pollution, 185: 77-83. PMID:24220023. doi:10.1016/j. envpol.2013.10.013.

Shah AA, Hasan F, Hameed A, and Ahmed S. 2008. Biological degradation of plastics: a comprehensive review. Biotechnology Advances, 26: 246-265. PMID:18337047. doi:10.1016/j.biotechadv.2007.12.005.

Silva-Cavalcanti JS, Silva JDB, de França EJ, de Araújo MCB, and Gusmão F. 2017. Microplastics ingestion by a common tropical freshwater fishing resource. Environmental Pollution, 221: 218226. doi:10.1016/j.envpol.2016.11.068.

Talsness CE, Andrade AJM, Kuriyama SN, Taylor J, and vom Saal FS. 2009. Components of plastic: experimental studies in animals and relevance for human health. Philosophical Transactions of the Royal Society B: Biological Sciences, 364: 2079-2096. PMID:19528057. doi:10.1098/rstb.2008.0281.

Teuten EL, Saquing JM, Knappe DRU, Barlaz MA, Jonsson S, Björn A, et al. 2009. Transport and release of chemicals from plastics to the environment and to wildlife. Philosophical Transactions of the Royal Society B: Biological Sciences, 364: 2027-2045. PMID:19528054. doi:10.1098/ rstb.2008.0284.

Wagner M, Engwall M, and Hollert H. 2014. Editorial: (micro)plastics and the environment. Environmental Sciences Europe, 26: 16-18. PMID:27752414. doi:10.1186/s12302-014-0016-3.

Wright SL, Thompson RC, and Galloway TS. 2013. The physical impacts of microplastics on marine organisms: a review. Environmental Pollution, 178: 483-492. PMID:23545014. doi:10.1016/j. envpol.2013.02.031.

Ziajahromi S, Neale PA, and Leusch FDL. 2016. Wastewater treatment plant effluent as a source of microplastics: review of the fate, chemical interactions and potential risks to aquatic organisms. Water Science and Technology, 74: 2253-2269. PMID:27858783. doi:10.2166/wst.2016.414.

Zitko V, and Hanlon M. 1991. Another source of pollution by plastics: skin cleansers with plastic scrubbers. Marine Pollution Bulletin, 22: 41-42. doi:10.1016/0025-326X(91)90444-W. 